\title{
Flow Injection Chemiluminescence Analysis of Some Penicillins by Their Sensitizing Effect on the Potassium Permanganate-Glyoxal Reaction
}

\author{
Yuanyuan Sun, * Yuhai TANG, ${ }^{* \dagger}$ Hong YAO, ${ }^{* *}$ and Yinhuan LI* \\ *Department of Chemistry, College of Science, Xi'an Jiaotong University, Xi'an 710061, P. R. China \\ **Department of Pharmaceutical Analysis, School of Pharmacy, Fujian Medical University, \\ Fuzhou 350004, P. R. China
}

\begin{abstract}
A new chemiluminescence method using flow injection is described for the determination of four penicillins, namely: phenoxymethylpenicillin potassium, amoxicillin, ampicillin, and ampicillin sodium. The method is based on sensitizing effect of these drugs on the chemiluminescence reaction of potassium permanganate in sulfuric acid with glyoxal. The different experimental parameters affecting the chemiluminescence intensity were carefully studied and incorporated into the procedure. The method allows the determination of $0.1-1.0 \mu \mathrm{g} / \mathrm{ml}$ phenoxymethylpenicillin potassium, $0.1-1.0$ $\mu \mathrm{g} / \mathrm{ml}$ amoxicillin, $0.1-1.0 \mu \mathrm{g} / \mathrm{ml}$ ampicillin, and $0.1-1.0 \mu \mathrm{g} / \mathrm{ml}$ ampicillin sodium. The method was successfully applied to the determination of four penicillin antibiotics in pharmaceutical preparations.
\end{abstract}

(Received February 27, 2004; Accepted November 29, 2004)

Penicillins, a kind of $\beta$-lactam antibiotics, are active on sensitive gram-positive and gram-negative organisms. Many analytical procedures have been reported for their determination. The Chinese Pharmacopoeia (2nd ed., 2000) recommends HPLC or titration assays for their dosages. ${ }^{1}$ Other reported methods include: spectrophotometry, ${ }^{2-4}$ mercurimetric titration, ${ }^{5} \mathrm{NMR},{ }^{6}$ HPLC, ${ }^{7-10}$ and HPLC-APCI-MS. ${ }^{11}$

There have been a few reports on chemiluminescence (CL) methods for the determination of penicillins. Jingshun et al. described a CL method for the determination of penicillin $\mathrm{G}$ with a linear range of $0.01-0.1 \mathrm{mg} / \mathrm{ml}$ and dicloxacillin with a linear range of $0.2-1.0 \mathrm{mg} / \mathrm{ml} .{ }^{12}$ It was based on the CL reaction of penicillins with potassium superoxide dissolved by 18-crown6-ether. Kubo et al. described a flow-injection CL method for the determination of $\beta$-lactam antibiotics, which was based on CL directly produced by the reaction of luminol with $\beta$-lactam antibiotics in the presence of a catalyst in an alkaline solution. The method allowed the determination of penicillin $\mathrm{G}$ in linear range of $0.12-6.0 \mathrm{mg} / \mathrm{ml}$ with a detection limit of $12 \mu \mathrm{g} / \mathrm{ml} .{ }^{13}$

The present article describes a simple flow injection CL method for the determination of four penicillins: phenoxymethylpenicillin potassium, amoxicillin, ampicillin, and ampicillin sodium. The method is based on an enhancing effect of penicillins on the CL reaction of glyoxal with $\mathrm{KMnO}_{4}$ in sulfuric acid. The experimental conditions for the reaction were optimized, and the final procedure allowed a successful determination of the studied drugs in pharmaceutical preparations.

\section{Experimental}

Reagents and chemicals

All of the reagents were of analytical reagent grade, and

† To whom correspondence should be addressed.

E-mail: tyh57@mail.xjtu.edu.cn doubly distilled water was used to prepare all solutions. Phenoxymethylpenicillin potassium, amoxicillin, ampicillin, and ampicillin sodium standard samples were purchased from National Institute for the Control of Pharmaceutical and Biological Products (Beijing, China). $\mathrm{KMnO}_{4}$ was obtained from Xi' an Chemical Reagent Factory (Xi'an, China). Glyoxal was provided by Department of Chemistry of Xi'an Jiaotong University (Xi'an, China).

The $1.0 \mathrm{mg} / \mathrm{ml}$ standard solutions of phenoxymethylpenicillin potassium, amoxicillin, ampicillin, and ampicillin sodium were freshly prepared by dissolving $250 \mathrm{mg}$ of each in water and diluting with water to $250 \mathrm{ml}$. The working solutions were prepared by appropriate dilution of these standard solutions with water before being used. A $\mathrm{KMnO}_{4}$ solution $1.0 \times 10^{-3} \mathrm{~mol} / \mathrm{l}$ was prepared by diluting an appropriate $0.1 \mathrm{~mol} / \mathrm{l}$ stock solution in $1.3 \mathrm{~mol} / 1 \mathrm{H}_{2} \mathrm{SO}_{4}$. A glyoxal solution $(0.05 \mathrm{~mol} / \mathrm{l})$ was prepared from a $1 \mathrm{~mol} / \mathrm{l}$ stock solution.

\section{Instruments}

The flow system used for the determination and CL detection for the studied penicillins is shown schematically in Fig. 1. One peristaltic pump (two channels) was used to drive $\mathrm{KMnO}_{4}$ in sulfuric acid and glyoxal solutions. Another peristaltic pump was used to deliver the sample solution. Each pump was run at with a constant flow rate of $2.75 \mathrm{ml} / \mathrm{min}$. PTFE tubing $(0.8 \mathrm{~mm}$ i.d.) was used to connect all components in the flow system. The CL signal produced was measured with a photomultiplier tube and recorded with an IBM-compatible computer, which was employed IFFL-D Model flow-injection CL analysis system software (Xi'an Ruike Electronic Equipment Corporation, Xi'an, China).

\section{Procedure for calibration}

A series of working solutions of four penicillin antibiotics with different concentrations were prepared by diluting concentrated standard solutions. As shown in Fig. 1, a $\mathrm{KMnO}_{4}$ solution in sulfuric acid and a glyoxal solution were pumped at 


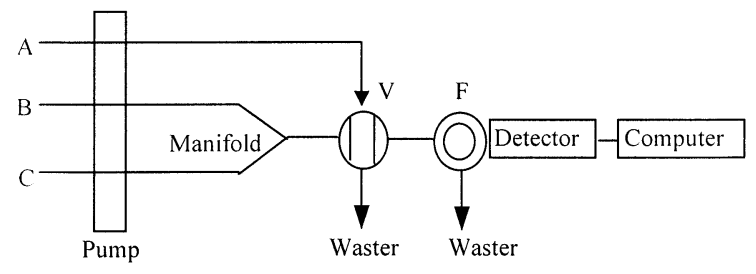

Fig. 1 Schematic diagram of the flow system for the determination of penicillins. A, sample solution; $\mathrm{B}, \mathrm{KMnO}_{4}$ solution; C, glyoxal solution; V, six-way injection valve; $\mathrm{F}$, flow cell.

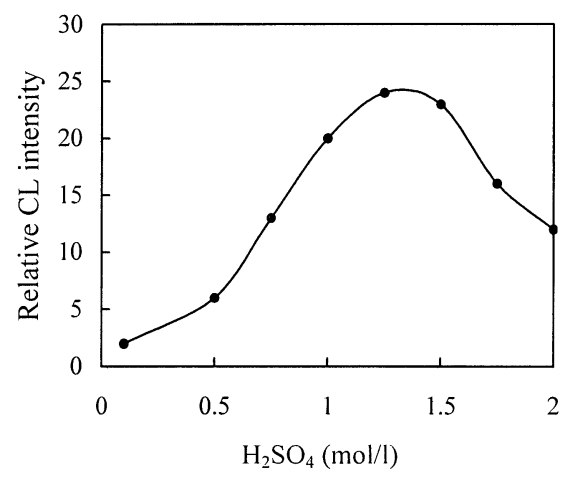

Fig. 2 Effect of the $\mathrm{H}_{2} \mathrm{SO}_{4}$ concentration of $\mathrm{KMnO}_{4}$ on the $\mathrm{CL}$ intensity (phenoxymethylpenicillin potassium $1.0 \mu \mathrm{g} / \mathrm{ml}$, glyoxal 0.05 $\left.\mathrm{mol} / \mathrm{l}, \mathrm{KMnO}_{4} 1.0 \times 10^{-3} \mathrm{~mol} / \mathrm{l}\right)$.

$2.75 \mathrm{ml} / \mathrm{min}$, and mixed with each other in a manifold. The sample solution was also pumped through another pump at 2.75 $\mathrm{ml} / \mathrm{min}$ and added into the flow cell with the aid of an injection valve with a $80 \mu \mathrm{l}$ sampling loop to combine with a mixed $\mathrm{KMnO}_{4}$-glyoxal solution. Calibration graphs were prepared by plotting the $C L$ peak height against the concentration of the penicillins.

\section{Analysis of the studied penicillins in pharmaceuticals}

Phenoxymethylpenicillin potassium tablets (250 mg/tablet), amoxicillin capsules ( $250 \mathrm{mg} / \mathrm{capsule}$ ), ampicillin capsules (250 $\mathrm{mg} /$ capsule), and ampicillin sodium for injection (500 $\mathrm{mg}$ /injection) were purchased from a local market. The average weight of each penicillin was calculated, respectively, from the weight of 10 capsules, tablets or injections. Each penicillin was finely powdered and homogenized; a portion of the powder, equivalent to $250 \mathrm{mg}$ of this penicillin, was accurately weighed and dissolved in $250 \mathrm{ml}$ of water as sample solutions. Before analysis, the sample solutions were diluted appropriately. The actual content of each penicillin was calculated from the corresponding regression equation.

\section{Results and Discussion}

\section{Effect of different acid concentrations}

It was observed that the $\mathrm{CL}$ signal of the $\mathrm{KMnO}_{4}$-glyoxal system was stronger in an acid solution than in a neutral or basic solution. Four different acids (i.e. $\mathrm{HCl}, \mathrm{HNO}_{3}, \mathrm{H}_{3} \mathrm{PO}_{4}$ and $\mathrm{H}_{2} \mathrm{SO}_{4}$ ) of different concentrations, as the media for $\mathrm{KMnO}_{4}$, over the range of $0.1-2.0 \mathrm{~mol} / \mathrm{l}$ were tested. The results showed that the maximum $\mathrm{CL}$ intensity was obtained with 1.3 $\mathrm{mol} / 1 \mathrm{H}_{2} \mathrm{SO}_{4}$ in $1.0 \times 10^{-3} \mathrm{~mol} / 1 \mathrm{KMnO}_{4}$. The effect of $\mathrm{H}_{2} \mathrm{SO}_{4}$ on the $\mathrm{CL}$ reaction is shown in Fig. 2.

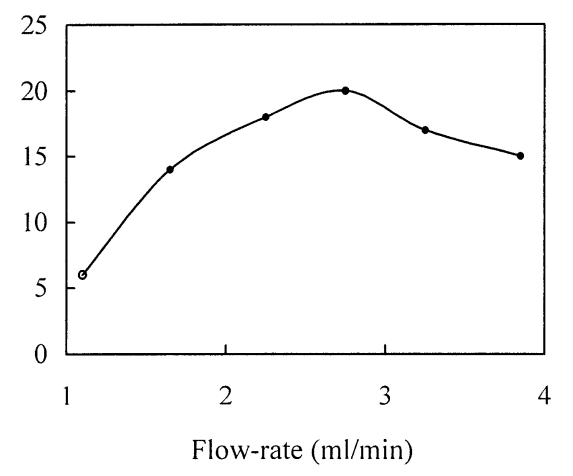

Fig. 3 Effect of the flow-rate on the CL intensity. (phenoxymethylpenicillin potassium $1.0 \mu \mathrm{g} / \mathrm{ml}, \mathrm{KMnO}_{4} 1.0 \times 10^{-3}$ $\mathrm{mol} / \mathrm{l}$, glyoxal $0.05 \mathrm{~mol} / \mathrm{l})$.

\section{Effect of the $\mathrm{KMnO}_{4}$ concentration}

The effect of $1.0 \times 10^{-4}-1.0 \times 10^{-2} \mathrm{~mol} / 1 \mathrm{KMnO}_{4}$ on the CL intensity was examined. The CL intensity continued to increase with increasing the $\mathrm{KMnO}_{4}$ concentration up to $1.0 \times 10^{-3} \mathrm{~mol} / \mathrm{l}$. The experimental results showed that $1.0 \times 10^{-3} \mathrm{~mol} / \mathrm{l}$ could give rise to a larger CL response and a lower background signal. A greater concentration $\mathrm{KMnO}_{4}$ could lower the CL intensity. Thus, $1.0 \times 10^{-3} \mathrm{~mol} / 1 \mathrm{KMnO}_{4}$ was used in the work.

\section{Effect of the glyoxal concentration}

The influence of the glyoxal concentration on the CL intensity was investigated in the range of 0.02 to $0.15 \mathrm{~mol} / \mathrm{l}$. It showed that the maximum increase in the relative CL intensity was obtained as the concentration of glyoxal increased up to 0.05 $\mathrm{mol} / \mathrm{l}$. Above $0.05 \mathrm{~mol} / \mathrm{l}$ of the glyoxal concentration, the increase in the relative CL intensity decreased. Therefore, $0.05 \mathrm{~mol} / \mathrm{l}$ of the glyoxal concentration was selected as being the optimum.

\section{Effect of the reagents flow-rate}

The flow rate of reagent solutions was tested in order to obtain a satisfactory CL peak. In this experiment, we controlled all of the solutions (glyoxal, $\mathrm{KMnO}_{4}$, and sample solutions) at the same flow rate, and changed the flow rate from $1.1 \mathrm{ml} / \mathrm{min}$ to $3.8 \mathrm{ml} / \mathrm{min}$ to study the effect of the flow rate on the CL intensity. Figure 3 shows the influence of the flow rate over the range $1.1-3.8 \mathrm{ml} / \mathrm{min}$. The results showed that, with $1.0 \mu \mathrm{g} / \mathrm{ml}$ phenoxymethylpenicillin potassium as the analyte when the concentration of glyoxal was at $0.05 \mathrm{~mol} / \mathrm{l}$, and $\mathrm{KMnO}_{4}$ was at $1.0 \times 10^{-3} \mathrm{~mol} / \mathrm{l}$, the $\mathrm{CL}$ intensity continued to increase with increasing flow-rate up to $2.75 \mathrm{ml} / \mathrm{min}$. A greater flow-rate could lower the $\mathrm{CL}$ intensity. In this work, $1.0 \times 10^{-3} \mathrm{~mol} / \mathrm{l}$ $\mathrm{KMnO}_{4}$ was selected.

\section{Calibration curves, detection limits and precisions}

Under the optimum conditions, four penicillin antibiotics were determined, respectively. The method allowed for the determination of $0.1-1.0 \mu \mathrm{g} / \mathrm{ml}$ phenoxymethylpenicillin potassium, amoxicillin, ampicillin, and ampicillin sodium with detection limits $(S / N=3)$ of $0.05 \mu \mathrm{g} / \mathrm{ml}$ phenoxymethylpenicillin potassium, $0.03 \mu \mathrm{g} / \mathrm{ml}$ amoxicillin, $0.03 \mu \mathrm{g} / \mathrm{ml}$ ampicillin, and $0.05 \mu \mathrm{g} / \mathrm{ml}$ ampicillin sodium.

The relative standard deviations for 11 replicate measurements of phenoxymethylpenicillin potassium, amoxicillin, ampicillin, and ampicillin sodium were $4.4,0.8$, 2.1 , and $1.1 \%$ when their concentrations were at $0.1 \mu \mathrm{g} / \mathrm{ml}$. Table 1 lists the parameters of the calibration curves and the calculated detection limits $(S / N=3)$. 
Table 1 Calibration curves of penicillins

\begin{tabular}{|c|c|c|c|c|c|}
\hline Species & Con. range ${ }^{\mathrm{a}} / \mu \mathrm{g} \mathrm{ml^{-1 }}$ & Calibration curve ${ }^{b}$ & $R^{2 \mathrm{c}}$ & Detection limit $/ \mu \mathrm{g} \mathrm{ml}^{-1}$ & $\mathrm{RSD}, \%^{\mathrm{e}}$ \\
\hline Phenoxymethylpenicillin potassium & $0.1-1$ & $y=5.14+38.6 x$ & 0.998 & 0.05 & 4.4 \\
\hline Amoxicillin & $0.1-1$ & $y=12.28+1.49 \times 10^{2} x$ & 0.998 & 0.03 & 0.8 \\
\hline Ampicillin & $0.1-1$ & $y=18.61+25.80 x$ & 0.999 & 0.03 & 2.1 \\
\hline Ampicillin sodium & $0.1-1$ & $y=0.13+2.17 \times 10^{2} x$ & 0.993 & 0.05 & 1.1 \\
\hline
\end{tabular}

a. Concentration range of the studied penicillins. b. Calibration curve; $y$ is the CL intensity and $x$ is the concentration of penicillins in $1 \mu \mathrm{g} / \mathrm{ml}$. c. Correlation coefficients. d. Detection limit; calculated as three-times the standard $(n=3)$ of the peak intensity. e. Relative standard deviations for 11 replicate measurements of penicillins; their concentrations were at $0.1 \mu \mathrm{g} / \mathrm{ml}$.

Table 2 Determination results of penicillins in pharmaceuticals

\begin{tabular}{|c|c|c|c|c|c|}
\hline \multirow{2}{*}{ Preparation } & \multirow{2}{*}{ Claimed/mg } & \multicolumn{2}{|c|}{ Proposed method } & \multicolumn{2}{|c|}{ Official method ${ }^{\mathrm{a}}$} \\
\hline & & Found/mg ${ }^{\mathrm{b}}$ & SD & Found/mg ${ }^{\mathrm{b}}$ & SD \\
\hline Phenoxymethylpenicillin potassium tablets & 250 & 243.0 & 0.9 & 252.8 & 0.3 \\
\hline Amoxicillin capsules & 250 & 237.8 & 0.2 & 252.5 & 0.2 \\
\hline Ampicillin capsules & 250 & 228.5 & 0.2 & 247.3 & 0.5 \\
\hline Ampicillin sodium for injection & 500 & 517.0 & 0.3 & 500.6 & 0.3 \\
\hline
\end{tabular}

a. Ref. 1. b. Mean value of five measurements.

\section{Interference study and application}

In order to assess the selectivity of the proposed method, the interference of some common inorganic ions and organic compounds on the CL reaction was examined by preparing solutions containing $1.0 \mu \mathrm{g} / \mathrm{ml}$ of phenoxymethylpenicillin potassium. The tolerance of foreign species was taken as the largest concentration, yielding an error of less than $\pm 5 \%$ in CL the signal of phenoxymethylpenicillin potassium. No interference was found when including up to a 1000 -fold $\mathrm{Na}^{+}$, $\mathrm{K}^{+}, \mathrm{Mg}^{2+}, \mathrm{Ba}^{2+}, \mathrm{Ca}^{2+}, \mathrm{SO}_{4}{ }^{2-}, \mathrm{NO}_{3}{ }^{-}$, glucose, starch, 100-fold $\mathrm{Zn}^{2+}, \mathrm{Al}^{3+}, 5$-fold $\mathrm{CO}_{3}^{2-}, 2$-fold $\mathrm{Cl}^{-}$.

The proposed method was successfully applied to the determination of phenoxymethylpenicillin potassium, amoxicillin, ampicillin, and ampicillin sodium in pharmaceutical formulations. The results are listed in Table 2, and agree well with those obtained by pharmacopoeia methods. ${ }^{1}$

\section{Discussion on a possible reaction mechanism}

It was reported that $\mathrm{KMnO}_{4}$ could react with some compounds (pyrogallol, ethamsylate and methotrexate) in the presence of formaldehyde or formic acid to produce ${ }^{1} \mathrm{O}_{2}{ }^{1} \mathrm{O}_{2}\left({ }^{1} \Delta_{\mathrm{g}}{ }^{1} \Delta_{\mathrm{g}}\right)$, a complex oxygen molecule having a single state, which could transform into ${ }^{3} \mathrm{O}_{2}\left({ }^{3} \Sigma_{\mathrm{g}}\right)$, a triplet state oxygen. During the transformation, it could produce $\mathrm{CL}$ and formaldehyde or formic acid, which could accelerate the oxidation reaction rate. ${ }^{14-16}$ It was also reported that the possible emitter of the hypochlorite-hydrogen peroxide CL systems was concerned with the singlet excited oxygen species. ${ }^{17}$ Thus, it is reasonable to assume that the singlet excited molecular oxygen species should also be the possible emitter in the present system. The formation of the singlet excited molecular oxygen may due to the oxidation of the $\beta$-lactam structure with the acidic potassium permanganate, and glyoxal could accelerate the CL reaction. In order to support this hypothesis, the CL spectrum of the system was detected with a modified RF-540 fluorescence spectrometer. The spectrum showed a wavelength maximum at $630 \mathrm{~nm}$. This wavelength maximum was shown to be similar to the spectrum attained for the above-mentioned CL systems.

In addition, Pang et al. studied the fluorescence spectrum of some penicillin antibiotics (benzathine benzylpenicillin, ampicillin, and carbenicillin) and their degradation products in the presence of $\mathrm{Mn}(\mathrm{II}){ }^{18}$ The results showed that the fluorescent intensities of the studied penicillin antibiotics in solutions was not detectable, but the fluorescent intensities of their degradation products could be detected. The maximum emission wavelengths of the spectrum of the degenerated products were over the range of $436-420 \mathrm{~nm}$. Obviously, since the maximum emission lengths of the spectrum for the degradation products did not agree with that of the CL reaction spectrum in our experiments, it does not support that the possible emitter was the reaction products of the penicillin antibiotics with acidic permanganate.

Based on the above discussions, the possible reaction mechanism was suggested to be as follows:

$$
\begin{aligned}
& \mathrm{MnO}_{4}{ }^{-}+\mathrm{H}^{+}+\text {glyoxal }+ \text { penicillins } \longrightarrow \\
& { }^{1} \mathrm{O}_{2}\left({ }^{1} \Delta_{\mathrm{g}}\right)+\mathrm{H}_{2} \mathrm{O}+\mathrm{Mn}(\mathrm{II})+\text { products } \\
& 2^{1} \mathrm{O}_{2}\left({ }^{1} \Delta_{\mathrm{g}}\right) \longrightarrow{ }^{1} \mathrm{O}_{2}{ }^{1} \mathrm{O}_{2}\left({ }^{1} \Delta_{\mathrm{g}}{ }^{1} \Delta_{\mathrm{g}}\right) \\
& { }^{1} \mathrm{O}_{2}{ }^{1} \mathrm{O}_{2}\left({ }^{1} \Delta_{\mathrm{g}} \Delta_{\mathrm{g}}\right) \longrightarrow \\
& { }^{3} \mathrm{O}_{2}\left({ }^{3} \Sigma_{\mathrm{g}}\right)+\mathrm{h} v
\end{aligned}
$$

\section{Conclsion}

Based on the chemiluminescence reaction of penicillins with $\mathrm{KMnO}_{4}$ in sulfuric acid and glyoxal, a new flow injection CL method was developed for the determination of these penicillins. The method was simple, rapid and sensitive, and was applied to the analysis of these penicillins in pharmaceutical preparations and compared with pharmacopoeia methods.

\section{Acknowledgements}

This work was financially supported by Xi'an Jiaotong University. 


\section{References}

1. Editorial Committee of the Pharmacopoeia of P. R. China. "The Pharmacopoeia of People's Republic of China", 2nd ed., 2000, Chemical Industry Press, Beijing.

2. H. Salem and G. A. Saleh, J. Pharm. Biomed. Anal., 2002 , $28,1205$.

3. C. S. P. Sastry, S. G. Rao, P. Y. Naidu, and K. R. Srinivas, Talanta, 1998, 45, 1227.

4. A. Fernández-González, R. Badía, and M. E. Díaz-García, J. Pharm. Biomed. Anal., 2002, 29, 669.

5. E. Roets, P. Rappe, M. Heeren, J. Hoebus, A. Verbruggen, and J. Hoogmartens, J. Pharm. Biomed. Anal., 1996, 14, 1141.

6. M. Shamsipur, Z. Talebpour, H. R. Bijanzadeh, and S. Tabatabaei, J. Pharm. Biomed. Anal., 2002, 30, 1075.

7. H. J. Mascher and C. Kikuta, J. Chromatogr., A, 1998, 812, 221.

8. P. O. Erah, B. A. Barrett, and P. N. Shaw, J. Chromatogr.,

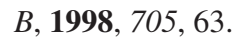

9. Y. Zhi, H. Q. Russlie, and D. M. Canafax, J. Chromatogr., $B, \mathbf{1 9 9 5}, 674,93$.

10. L. K. Sørensen, L. K. Snor, T. Elkær, and H. Hansen, J. Chromatogr., B, 1999, 734, 307.

11. S. Horimoto, T. Mayumi, K. Aoe, N. Nishimura, and S. Tadashi, J. Pharm. Biomed. Anal., 2002, 30, 1093.

12. J. S. Sun, S. G. Schulman, and J. H. Perrin, Anal. Chim. Acta, 1997, 338, 1.

13. H. Kubo, M. Saitoh, T. Inomata, Y. Yoshimura, and H. Nakazawa, Anal. Chim. Acta, 1999, 389, 89.

14. A. Townshend, J. A. Murillo Pulgarín, and M. T. Alañón Pardo, Anal. Chim. Acta, 2003, 488, 81.

15. J. X. Du, Y. H. Li, Y. Tang, and J. R. Lu, Anal. Lett., 2002 , $35,463$.

16. Y. H. He, Y. Y. Xue, M. L. Feng, and J. R. Lu, Chin. J. Anal. Chem., 1998, 26, 1136.

17. A. U. Khan and M. Kasha, J. Am. Chem. Soc., 1970, 92, 3293.

18. Z. T. Pang, C. N. Yang, and Y. T. Wang, Chin. J. Anal. Lab., 2001, 4, 1. 